\title{
Correction to: Identifying Predictors of Momentary Negative Affect and Depression Severity in Adolescents with Autism: An Exploratory Ecological Momentary Assessment Study
}

\author{
Aaron R. Dallman ${ }^{1}$ D . Antoine Bailliard ${ }^{2} \cdot$ Clare Harrop $^{2}$
}

Published online: 11 October 2021

○) Springer Science+Business Media, LLC, part of Springer Nature 2021

\section{Correction to: \\ Journal of Autism and Developmental Disorders https://doi.org/10.1007/s10803-021-04935-8}

There were several errors in the editorial process that resulted in citations being erroneously admitted in the methods description. The corrected paragraphs and citations are below.

\section{Methods}

Participants were 17 male autistic adolescents aged 11-17 years $(\mathrm{M}=14$ years, $\mathrm{SD}=2$ years) (see Table 1$)$. Participants were recruited via The University of North Carolina at Chapel Hill ASD Research Registry. Registry participants are referred through collaborative relationships with other university affiliated institutions that serve individuals with autism. To qualify for the research registry, all participants had undergone extensive observation and clinical testing for an autism diagnosis, including gold-standard diagnostic assessments and interviews such as the Autism Diagnostic Interview- Revised (Lord et al., 1994), Autism Diagnostic Observation Schedule, second edition (Lord et al., 2012), and Childhood Autism Rating Scale (Schopler et al., 2010). Inclusion criteria were as follows: participants

The original article can be found online at https://doi.org/10.1007/ s10803-021-04935-8.

Aaron R. Dallman

adallman@towson.edu

1 Department of Occupational Therapy and Occupational Science, College of Health Professions, Towson University, 8000 York Rd, Towson, MD, USA

2 Department of Allied Health Sciences, School of Medicine, University of North Carolina at Chapel Hill, Chapel Hill, NC, USA resided in Central and Eastern North Carolina, confirmed clinical diagnosis of ASD, had a composite abbreviated intelligence quotient greater than 85, spoke fluent English, and had regular access to a mobile phone. Participants with co-occurring genetic syndromes were excluded from the study. Females were excluded due to the small sample size, the observed prevalence of ASD being much higher in males than females (1:4), and the exploratory nature of this study.

\section{Positive and Negative Affect Scale, Children's Version, Short Form (PANAS-C-SF)}

Adolescents completed the positive and negative affect scale, short form (PANAS-C-SF) (Ebesutani et al., 2012; Sanmartín et al., 2018) to assess momentary positive affect and negative affect. Adolescents completed the 10-item measure, indicating on a four-point scale to what extent they are experiencing a particular emotion: none at all, a little, some, a lot

\section{References}

Ebesutani, C., Regan, J., Smith, A., Reise, S., Higa-McMillan, C., \& Chorpita, B. F. (2012). The 10-item positive and negative affect schedule for children, child and parent shortened versions: Application of item response theory for more efficient assessment. Journal of Psychopathology and Behavioral Assessment, 34, 191-203. https://doi.org/10.1007/s10862-011-9273-2

Lord, C., Rutter, M., Dilavore, P. C., Risi, S., Gotham, K., \& Bishop, S. L. (2012). Autism Diagnostic Observation Schedule ${ }^{T M}$, second edition (ADOS ${ }^{T M}$-2) manual (Part I): Modules 1-4. Western Psychological Services.

Lord, C., Rutter, M., \& Le Couteur, A. (1994). Autism diagnostic interview-revised: A revised version of a diagnostic interview for caregivers of individuals with possible pervasive developmental disorders. Journal of Autism and Developmental Disorders, 24(5), 659-685. https://doi.org/10.1007/BF02172145 
Schopler, E., Van Bourgondien, M. E., Wellman, G. J., \& Love, S. R. (2010). (CARS ${ }^{T M}$-2) Childhood Autism Rating Scale ${ }^{T M}$. Western Psychological Services.
Publisher's Note Springer Nature remains neutral with regard to jurisdictional claims in published maps and institutional affiliations. 